\title{
Recurrent Digestive System Neuroendocrine Carcinoma
}

National Cancer Institute

\section{Source}

National Cancer Institute. Recurrent Digestive System Neuroendocrine Carcinoma. NCI

Thesaurus. Code C155938.

The reemergence of a neuroendocrine carcinoma in any part of the digestive system after a period of remission. 